\title{
ATENOLOL DEPRESSES POST-ISCHAEMIC RECOVERY IN THE ISOLATED RAT HEART
}

\author{
SONIA ALLIBARDI ${ }^{\mathrm{a}}$, GIAMPIERO MERATI ${ }^{\mathrm{b}}$, SERGIO CHIERCHIA $^{\mathrm{c}}$ and \\ MICHELE SAMAJA ${ }^{\mathrm{a}, *}$
${ }^{a}$ Dipartimento di Scienze e Tecnologie Biomediche, Università di Milano, via Cervi 93, I-20090 Milano, Italy, ${ }^{b}$ Cattedra di Fisiologia, Università di Brescia, Brescia, Italy and ${ }^{c}$ Istituto San Raffaele, Milano, Italy

Accepted 22 December 1998

\begin{abstract}
Metabolic events during ischaemia are probably important in determining post-ischaemic myocardial recovery. The aim of this study was to assess the effects of the $\beta$-blocker atenolol and the high energy demand in an ischaemia-reperfusion model free of neurohormonal and vascular factors. We exposed Langendorff-perfused isolated rat hearts to low-flow ischaemia $(30 \mathrm{~min})$ and reflow $(20 \mathrm{~min})$. Three groups of hearts were used: control hearts $(n=11)$, hearts that were perfused with $2.5 \mu \mathrm{g} \mathrm{l} \mathrm{l}^{-1}$ atenolol $(n=9)$, and hearts electrically paced during ischaemia to distinguish the effect of heart rate from that of the drug $(n=9)$. The hearts were freeze-clamped at the end of reflow to determine high-energy phosphates and their metabolites. During ischaemia, the pressure-rate product was $2.3 \pm 0.2$, $5.2 \pm 1.1$, and $3.3 \pm 0.3 \mathrm{mmHg} 10^{3} \mathrm{~min}$ in the control, atenolol and paced hearts, respectively. In addition, the ATP turnover rate, calculated from venous (lactate), oxygen uptake and flow, was higher in atenolol $\left(11.2 \pm 1.7 \mu \mathrm{mol} \mathrm{min}^{-1}\right)$ and paced $\left(8.1 \pm 0.8 \mu \mathrm{mol} \mathrm{min}^{-1}\right)$ hearts than in control $\left(6.2 \pm 0.8 \mu \mathrm{mol} \mathrm{min}{ }^{-1}\right)$. At the end of reflow, the pressure $\times$ rate product recovered $75.1 \pm 6.4 \%$ of baseline in control us $54.1 \pm 9.1$ and $48.8 \pm 4.4 \%$ in atenolol and paced hearts $(P<0.05)$. In addition, the tissue content of ATP was higher in the control hearts $\left(15.8 \pm 1.0 \mu \mathrm{mol} \mathrm{g}_{\mathrm{dw}}^{-1}\right)$ than in atenolol $(10.5 \pm 2.6 \mu \mathrm{mol} \mathrm{g}-1$ dw $)$ and paced $\left(10.9 \pm 1.3 \mu \mathrm{mol} \mathrm{g}_{\mathrm{dw}}^{-1}\right)$ hearts. Thus, by suppressing the protective effects of down-regulation, both atenolol and pacing apparently depress myocardial recovery in this model.
\end{abstract}

(C) 1999 Academic Press

KEY wORDS: low-flow ischaemia, $\beta$-blocker, bioenergetics, high-energy phosphates.

\section{INTRODUCTION}

Post-ischaemic myocardial recovery depends on several not yet clarified factors, but metabolic events during ischaemia are probably important [1]. Ischaemic down-regulation of contractility plays a key role in linking metabolism during ischaemia to mechanical recovery during reflow. The total tissue contents of adenine nucleotides and purines (TANP) are maintained in isolated rat hearts during $90 \%$ flow reduction if myocardial activity is down-regulated [2]. This feature, that improves post-ischaemic recovery regardless of free radicals scavenging [3], is attributed to energy demand-to-supply matching. Coronary flow disturbs down-regulation: when nor-

\footnotetext{
* Corresponding author.
}

mal-flow hypoxemia replaces low-flow ischaemia, the beneficial effects of down-regulation are suppressed [4]. However, the role of energy demand during ischaemia is still unclear despite its relevance in pharmacological treatments that involve modulation of myocardial contractility.

$\beta$-blockers are commonly used for the treatment of ischaemic heart disease [5]. Besides their neurohormonal [6, 7] and platelet-inhibiting effects [8], they decrease myocardial $\mathrm{O}_{2}$ consumption [9] and enhance carbohydrate metabolism and energy production $[10,11]$. Atenolol, a selective $\beta-1$ adrenergic antagonist [12] with specific effect on $\mathrm{Ca}^{2+}$ currents [13] and intracellular acidosis [14], enhances mitochondrial ATPase activity [15]. Although $\beta$-blockers, propranolol and metoprolol, reduce episodes of transient myocardial ischaemia [16], atenolol apparently does not protect against ischaemia-reperfusion 
in a model of isolated perfused heart exposed to global no-flow ischaemia [17].

The aims of this study are: (1) to assess the metabolic effects of atenolol in an ischaemia-reperfusion model free of neurohormonal and vascular factors; and (2) to use atenolol as a probe to examine the effect of energy demand on post-ischaemic recovery in the same way as hypoxemia helps to understand the effect of coronary flow. Thus, besides its pharmacological value, this study may help to assess whether drug-induced changes in energy demand during ischaemia altered energy demandto-supply matching and recovery. As the heart rate was a disturbing variable between control and atenolol-perfused hearts, we also studied the effects of this variable in the absence of the drug. We show that, by increasing energy demand during ischaemia, neither atenolol nor electrical pacing are beneficial during reflow, as reflected by a depressed performance and tissue level of high-energy phosphates. This confirms that down-regulation of energy demand during ischaemia is an effective way to protect the myocardium.

\section{MATERIALS AND METHODS}

\section{Heart perfusion}

Apparatus and procedures are described elsewhere [4]. Briefly, CD outbred rats (Charles River, Calco, Italy, weight 250-270 g) were anaesthetised, hearts were excised and immediately perfused. The medium (Krebs-Henseleit buffer, $2 \mathrm{mM}$ free $\mathrm{Ca}^{2+}$, $11 \mathrm{~mm}$ glucose $)$ was oxygenated $\left(\mathrm{PO}_{2}=670 \mathrm{mmHg}\right)$ in membrane oxygenators. When specified, $2.5 \mu \mathrm{g}$ $1^{-1}$ atenolol (Sigma Chemicals, St. Louis, MO) was added to the medium. A peristaltic pump (Minipuls 3, Gilson, France) delivered the medium to a preheater $\left(37^{\circ} \mathrm{C}\right)$ and the aortic cannula. We monitored the coronary perfusion pressure by a pressure transducer (Harvard Apparatus, mod 52-9966, Natick, MA) connected to the aortic cannula. Heart rate (HR), developed pressure (LVDP), end-diastolic pressure (EDP), maximal rate of pressure development $\left(+\mathrm{d} P / \mathrm{d} t_{\text {max }}\right)$ and relaxation $\left(-\mathrm{d} P / \mathrm{d} t_{\text {max }}\right)$ were monitored by a pressure transducer connected to the intraventricular balloon. A cannula inserted in the pulmonary artery was used to collect the venous outflow for measurement of lactate (Sigma Diagnostics, St. Louis, MO) and $\mathrm{PO}_{2}$ (YSI mod 5300 Oxygen Monitor, Yellow Springs Inc, OH). Stimulation electrodes (Harvard, South Natick, MA, Square wave stimulator, $5 \mathrm{~ms}$ pulse duration, $10 \mathrm{~V}$ pulse amplitude) were placed on the aortic cannula and on the apex of the ventricle. An Apple Macintosh Quadra 700 (Cupertino, CA) was used to acquire data (LabView 3.0, National Instruments, Austin, TX) and to control the speed of the peristaltic pump
(NB-MIO-16 Multifunction I/O Board, National Instruments, Austin, TX).

\section{Experimental design}

The hearts were equilibrated for $20 \mathrm{~min}$ at a perfusion pressure of $100 \mathrm{mmHg}$ and the volume of the intraventricular balloon was fixed to yield an $\mathrm{EDP}=8-9 \mathrm{mmHg}$. After baseline measurements, hearts were exposed to ischaemia for $30 \mathrm{~min}$ by decreasing the pump speed to yield a perfusion pressure of $10 \mathrm{mmHg}$. Measurements were taken at the end of ischaemia with stable myocardial performance. Hearts were then reperfused for $20 \mathrm{~min}$ under the same conditions of baseline, measurements were taken again, and hearts were freezeclamped for metabolic assays. Hearts were divided into three groups: control $(n=11)$, atenolol $(n=9$, $2.5 \mu \mathrm{g}^{-1}$ atenolol in the medium), and paced ( $n=9$, electrically paced during ischaemia at $160 \pm 6$ $\min ^{-1}$ ). An additional group (atenolol and paced, $n=9$ ) was designed to monitor the simultaneous effects of atenolol and pacing.

\section{Metabolic measurements}

Freeze-clamped tissue was assayed for ATP, ADP, AMP, adenosine, inosine-5'-monophosphate, inosine, hypoxanthine, xanthine, urate, phosphocreatine and creatine by high-pressure liquid chromatography [18]. Calculations include: TANP (sum of these substances except phosphocreatine and creatine), $\mathrm{O}_{2}$ uptake $\left(\mathrm{VO}_{2}\right.$, from flow, arterial and venous $\left.\mathrm{PO}_{2}\right)$, net lactate release $\left[\mathrm{J}_{\mathrm{lac}}=\right.$ venous $($ lactate $) \cdot$ flow $]$, ATP turnover rate $\left(\mathrm{J}_{\mathrm{ATP}}=\mathrm{J}_{\text {lac }}+6 \cdot V_{\mathrm{O}_{2}}\right)$ e.g. assuming ATP $/$ lactate $=1.0$ (glucose as the only substrate without significant glycogenolysis) and ATP $/ \mathrm{O}_{2}$ ratio $=6$ (no mitochondrial uncoupling).

\section{Statistics}

Data are expressed as mean \pm SE. One-way ANOVA followed by the Fisher's multiple comparison test was performed (StatView 4 software, Abacus Concepts, Inc, Berkeley, CA), with the significance level set at $P=0.05$ (two-tailed).

\section{RESULTS}

All hearts of the three main groups kept contracting throughout the protocol and are suitable for statistical analysis. In contrast, atenolol and paced hearts generally stopped contracting during ischaemia and could not be considered any further. Table I shows that $2.5 \mu \mathrm{g}^{-1}$ atenolol did not affect performance during baseline perfusion in this model.

When perfusion pressure was reduced to 10 $\mathrm{mmHg}$, coronary flow was $0.8-0.9 \mathrm{ml} \mathrm{min}^{-1}$ in the control and paced groups, us $1.2 \mathrm{ml} \mathrm{min}^{-1}$ in the 
Table I

Baseline performance (mean $\pm \mathrm{SE}$ ) and effect of $2.5 \mu \mathrm{g} \mathrm{I}^{-1}$ atenolol at perfusion pressure $=100 \mathrm{mmHg}$, arterial $\mathrm{Po}=670$ mmHg. No significant differences were detected

\begin{tabular}{lcc}
\hline Parameter & Control & Atenolol \\
\hline$n$ & 20 & 9 \\
Coronary flow $\left(\mathrm{ml} \mathrm{min}^{-1}\right)$ & $12.3 \pm 0.6$ & $12.5 \pm 0.7$ \\
Heart rate $\left(\mathrm{min}^{-1}\right)$ & $234 \pm 5$ & $233 \pm 8$ \\
End-diastolic pressure $(\mathrm{mmHg})$ & $9.0 \pm 0.5$ & $8.1 \pm 0.8$ \\
Developed pressure $\left(\mathrm{mmHg}^{2}\right)$ & $119 \pm 5$ & $3659 \pm 163$ \\
Maximal rate of contraction $\left(\mathrm{mmHg} \mathrm{s}^{-1}\right)$ & $2076 \pm 294$ & $2354 \pm 69$ \\
Maximal rate of relaxation $\left(\mathrm{mmHg} \mathrm{s}^{-1}\right)$ & $6.7 \pm 0.4$ & $6.9 \pm 0.4$ \\
Oxygen uptake $\left(\mu \mathrm{mol} \mathrm{min}^{-1}\right)$ & $<0.1$ & $<0.1$ \\
Lactate efflux $\left(\mu \mathrm{mol} \mathrm{min}^{-1}\right)$ & $40.2 \pm 2.4$ & $41.4 \pm 2.6$ \\
ATP production rate $\left(\mu \mathrm{mol} \mathrm{min}^{-1}\right)$ & & \\
\hline
\end{tabular}

atenolol group $(P=0.03)$. Thus, atenolol decreased coronary resistance during low-flow ischaemia from $15.3 \pm 2.6 \mathrm{mmHg} \operatorname{min~} \mathrm{ml}^{-1}$ to $8.2 \pm 1.3 \mathrm{mmHg} \min$ $\mathrm{ml}^{-1}(P=0.03)$. During low-flow ischaemia, atenolol induced a higher HR and lower LVDP, $+\mathrm{d} P / \mathrm{d} t_{\text {max }}$ and $-\mathrm{d} P / \mathrm{d} t_{\max }$ than in control hearts (Fig. 1). However, the (pressure $\times$ rate) product was $2.3 \pm 0.2$ and $5.2 \pm 1.1 \mathrm{mmHg} 10^{3} \mathrm{~min}(P=0.01)$ in control and atenolol hearts.

To distinguish the effects of HR from those of the drug, paced hearts were stimulated at the same HR

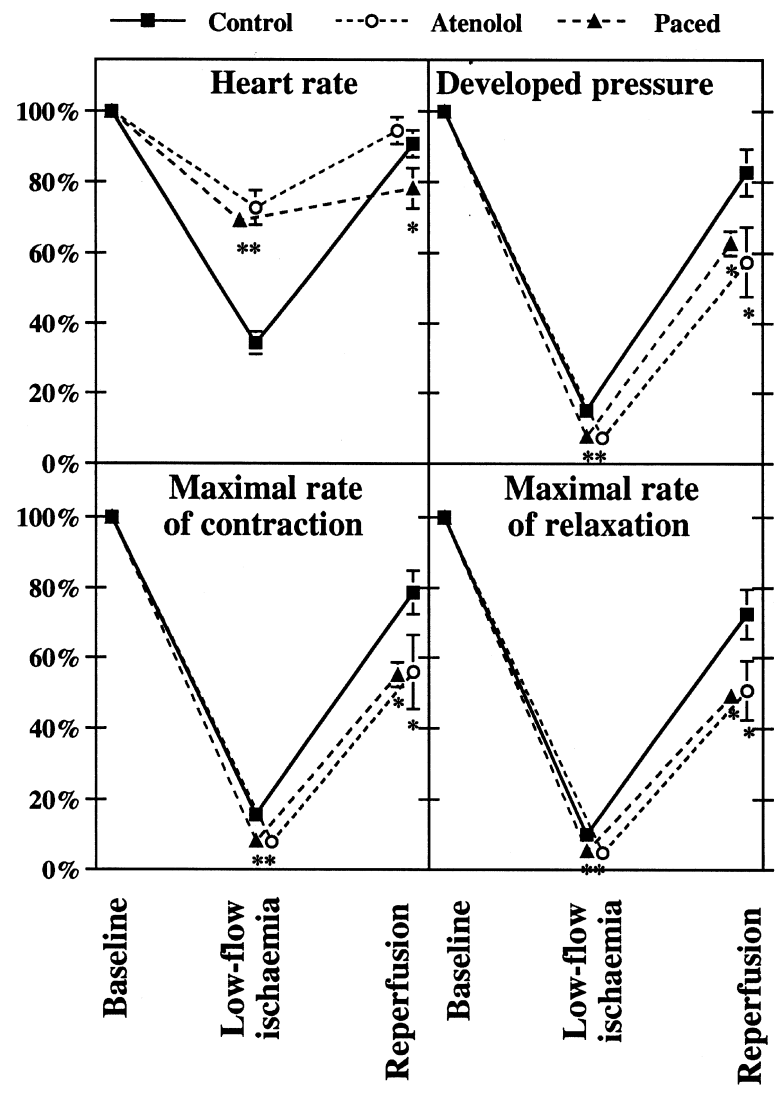

Fig. 1. Heart rate, developed pressure, maximal rates of contraction and relaxation in control, atenolol-perfused and paced hearts. Vertical bars represent SE. ${ }^{*} P<0.05$ vs control (ANOVA and Fisher's post-tests). as that found in atenolol hearts. In these hearts, LVDP, $+\mathrm{d} P / \mathrm{d} t_{\text {max }}$ and $-\mathrm{d} P / \mathrm{d} t_{\text {max }}$ were the same as in atenolol hearts. The (pressure $\times$ rate) product was $3.3 \pm 0.3 \mathrm{mmHg} 10^{3} \mathrm{~min}(P=0.01$ vs control, $P=$ NS vs atenolol $)$.

During ischaemia, venous (lactate) and lactate efflux were higher in atenolol and paced hearts than in control hearts (Fig. 2). By contrast, $V_{\mathrm{O}_{2}}$ was higher than normal in atenolol hearts only, whilst in paced hearts $\mathrm{VO}_{2}$ was similar to control. When $\mathrm{J}_{\text {ATP }}$ is calculated as described, it was similar in paced and control hearts, but higher in atenolol hearts.

During reflow, the recovery of mechanical perfor-

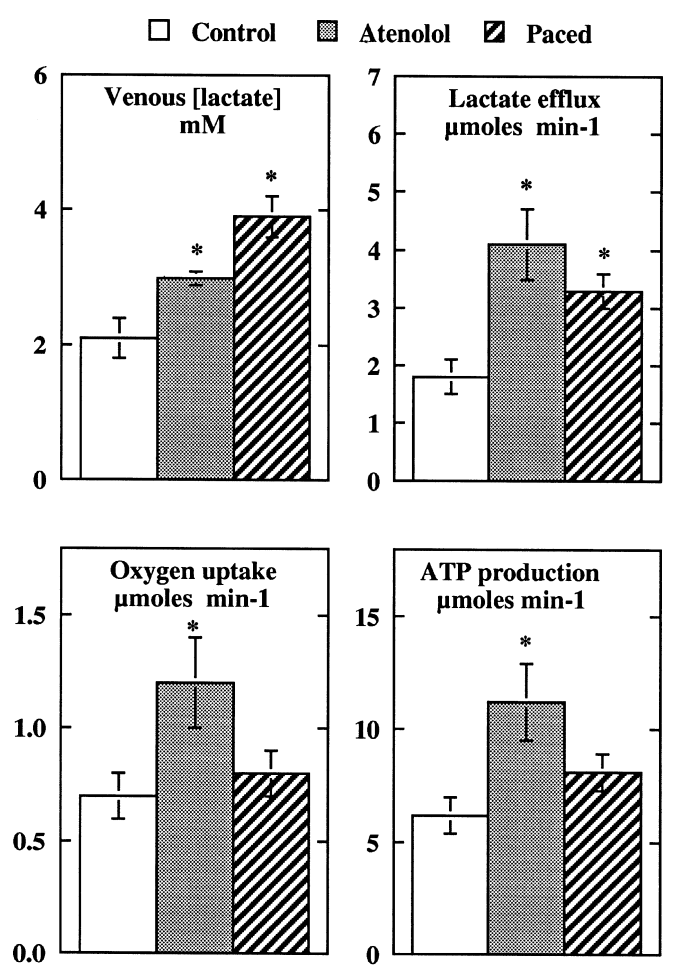

Fig. 2. Venous (lactate), lactate efflux, oxygen uptake and ATP production rate measured at the end of the ischaemia period in control, atenolol-perfused and paced hearts. Vertical bars represent SE. ${ }^{*} P<0.05$ vs control (ANOVA and Fisher's post-tests). 

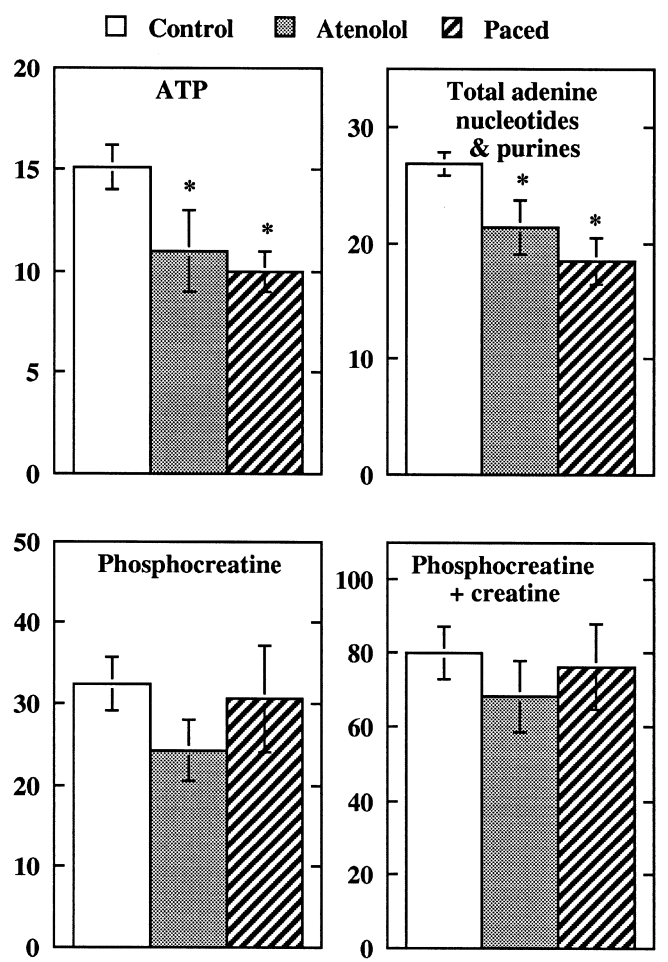

Fig. 3. Tissue content of ATP, total adenine nucleotides and purines, phosphocreatine, and phosphocreatine + creatine measured at the end of reflow in control, atenolol-perfused and paced hearts. Vertical bars represent SE. ${ }^{*} P<0.05$ vs control (ANOVA and Fisher's posttests).

mance was impaired in both atenolol and paced hearts. The tissue contents of ATP and TANP reflected mechanical recovery, but the content of phosphocreatine and phosphocreatine + creatine was the same in the three groups. The level of inosine-5'-monophosphate was $0.35 \pm 0.14,1.07 \pm$ 0.49 , and $0.25 \pm 0.14 \mu \mathrm{mol} \mathrm{g} \mathrm{dw}_{\mathrm{dw}}^{-1}$ in control, atenolol and paced hearts (Fig. 3).

\section{DISCUSSION}

Due to its relatively low dose $\left(2.5 \mu \mathrm{g} \mathrm{l^{-1 }}\right.$, or $\approx 10^{-8}$ $\mathrm{M}$ ), atenolol did not cause any measurable effect during baseline perfusion (Table I). Therefore, all the features observed in this study are directly related to the effects caused by atenolol on heart metabolism throughout ischaemia-reperfusion, thereby ruling out the well known effects related to $\beta$-blockade. Indeed, despite low dose, after reperfusion atenolol hearts display increased $\mathrm{HR}$, flow, $\mathrm{J}_{\mathrm{Lac}}$, $V \mathrm{O}_{2}$ and $\mathrm{J}_{\mathrm{ATP}}$, with decreased LVDP, $+\mathrm{d} P / \mathrm{d} t_{\max }$ and $-\mathrm{d} P / \mathrm{d} t_{\max }$ with respect to control hearts. The features observed in atenolol hearts are practically superimposable to those observed in hearts electrically paced to increase energy demand.

\section{Model}

The employed atenolol concentration allowed us to compare our results to those of previous studies $[8,11,16,19,20]$. The selected ischaemia condition induces reproducible myocardial dysfunction in control hearts without leading to arrest. This is essential to seek correlations between ischaemic down-regulation and recovery. Lack of blood in the perfusion medium excluded possible effects of atenolol on neutrophil accumulation and thrombin-induced platelet aggregation, thereby stressing its effects on cardiac metabolism. Strict temperature control $\left( \pm 0.5^{\circ} \mathrm{C}\right)$, same volume of the intraventricular balloon, and same perfusion pressure in the various groups ruled out differences in loading conditions. As animals were not pretreated, these observations relate to acute metabolic effects of atenolol on cardiac muscle.

\section{Ischaemic down-regulation and recovery}

In untreated hearts during low-flow ischaemia, flow was $7-11 \%$ of baseline in all groups. This condition is known to induce myocardial down-regulation [4], probably due to intracellular lactate accumulation, which depresses metabolism and performance independently of $\mathrm{pH}$ [21]. By decreasing energy demand with respect to supply, ischaemic down-regulation would favour energy supply-to-demand matching and improve ATP/ADP coupling. This would maintain the ATP pool during ischaemia and improve recovery during reflow $[2,22]$.

Ischaemic down-regulation is apparently suppressed in atenolol hearts. In these hearts, the rates of both aerobic $\left(V_{\mathrm{O}_{2}}\right)$ and anaerobic $\left(\mathrm{J}_{\mathrm{Lac}}\right)$ paths during ischaemia are increased, thereby increasing $\mathrm{J}_{\mathrm{ATP}}$, in agreement with previous observations [9-11]. Moreover, the (pressure $\times$ rate) product reflects more than double the energy demand. This increase can not be accounted for by the $40-50 \%$ higher flow and supply of $\mathrm{O}_{2}$.

Suppression of down-regulation in atenolol hearts accounts, at least in part, for impaired recovery. The lower contractility is accompanied by depressed ATP and TANP contents. High inosine-5'-monophosphate levels in atenolol hearts also indicate severe metabolic dysfunction [23]. Phosphocreatine and creatine do not leak across intact membrane [24], thus the preservation of these compounds throughout ischaemia-reflow indicates that the fall observed for ATP and TANP is not due to physical membrane damage, but rather to the membrane-diffusibility of these compounds [2].

The pattern observed in paced hearts reproduces that observed in atenolol hearts: high (pressure $\times$ rate) during ischaemia indicates suppression of down-regulation. This worsens the energy supplyto-demand imbalance, thereby impairing recovery during reflow. This chain of events closely resembles the one observed in hypoxemic hearts in previous 
studies [2]. Thus, myocardial ischaemic down-regulation may be disturbed by several events, including atenolol, electrical pacing and hypoxemia, all of which have the common feature to increase energy demand during the ischaemic stress.

\section{Conclusion}

Atenolol depresses post-ischaemic recovery in isolated perfused hearts independently of neurohormonal and blood-related effects. This effect is apparently due to the suppression of ischaemic down-regulation, which was shown to improve myocardial tolerance to ischaemia through better preservation of the high-energy phosphate pools [22]. Down-regulation during ischaemia may therefore play a central role in the ischaemia-reperfusion syndrome. This further stresses the importance of myocardial metabolism in determining mechanical recovery during reflow.

\section{ACKNOWLEDGEMENT}

Work partly supported by MURST, ex 40\% 'Molecular and metabolic lesions induced by post-ischaemic myocardial reperfusion'.

\section{REFERENCES}

1. Opie LH. Cardiac metabolism-emergence, decline and resurgence. Part II. Cardiovasc Res 1992; 26: 817-30.

2. Samaja M, Motterlini R, Allibardi S, Casalini S, Merati G, Corno A, Chierchia S. Myocardial metabolism and function in acutely ischemic and hypoxemic isolated rat hearts. J Mol Cell Cardiol 1995; 27: 1213-8.

3. Samaja M, Motterlini R, Santoro F, Dell'Antonio G, Corno A. Oxidative injury in reoxygenated and reperfused hearts. Free Rad Biol Med 1994; 16: 255-62.

4. Samaja M, Casalini S, Allibardi S, Corno A, Chierchia S. Regulation of bioenergetics in $\mathrm{O}_{2}$-limited isolated rat hearts. J Appl Physiol 1994; 77: 2530-6.

5. Chierchia S, Fragasso G. Metabolic management of ischaemic heart disease. Eur Heart $J$ 1993; 14 Suppl.G: $2-5$.

6. Kjekshus JK. Importance of heart rate in determining $\beta$-blocker efficacy in acute and long-term myocardial infarction intervention trials. Am J Cardiol 1986; 57: 43-9.

7. Andersson B, Lomsky M, Waagstein F. The link between acute haemodynamic adrenergic $\beta$-blockade and long-term effects in patients with heart failure. Eur Heart J 1993; 14: 1375-85.

8. Winther K, Willich SN. $\beta_{1}$-blockade and acute coronary ischemia. Possible role of platelets. Circulation 1991; 84 Suppl. VI: 68-71.
9. Jackson G, Atkinson L, Oram S. Improvement of myocardial metabolism in coronary arterial disease by $\beta$-blockade. Br Heart J 1977; 39: 829-33.

10. Nielsen TT, Bagger JP, Thomassen A. Improved myocardial lactate extraction after propanolol in coronary artery disease: effected by peripheral glutamate and free fatty acid metabolism. Br Heart J 1986; 55: 140-7.

11. Thompson DS, Naqvi N, Juul SM, Coltart DJ, Jenkins BS, Webb-Peploe MM. Haemodynamic and metabolic effects of atenolol in patients with angina pectoris. Br Heart J 1980; 43: 668-79.

12. Barret AM. The pharmacology of atenolol. Postgrad Med J 1977; 53 Suppl. 3: 58-64.

13. Mewes T, Dutz S, Ravens U, Jakobs KH. Activation of calcium currents in cardiac myocytes by empty $\beta$-adrenoceptors. Circulation 1993; 88: 2916-22.

14. Shida S, Nakaya $\mathrm{H}$, Matsumoto $\mathrm{S}$, Kanno M. $\beta_{1}$ Adrenoceptor mediated decrease in $\mathrm{pH}_{\mathrm{i}}$ in quiescent ventricular myocardium. Cardiovasc Res 1994; 28: 112-8.

15. Almotrefi AA, Dzimiri N. Effects of b-adrenoceptor blockers on mitochondrial ATPase activity in guinea pig heart preparations. Eur J Pharmacol 1992; 215: 231-6.

16. Chierchia S, Muiesan L, Davies A, Balasubramian V, Gerosa S, Raftery EB. Role of sympathetic nervous system in the pathogenesis of chronic stable angina. Implications for the mechanism of action of $\beta$-blockers. Circulation 1990; 82 Suppl. II: 71-81.

17. Singh N, Seneviratne CK, Singal PK. Propranolol protection against ischemic injury is accompanied by increase in antioxidant activities without any change in mRNA. FASEB J 1995; 9: A420 (Abstract).

18. Motterlini R, Samaja M, Tarantola M, Micheletti R, Bianchi G. Functional and metabolic effects of propionyl-L-carnitine in the isolated perfused hypertrophied rat heart. Mol Cell Biochem 1992; 116: 139-45.

19. Ruskoako H. Effect of atenolol and pindolol on the phorbol ester-induced coronary vasoconstriction in the isolated perfused heart of the rat. Br J Pharmacol 1988; 94: 573-83.

20. Schulz R, Rose J, Skyschally A, Heusch G. Bradycardic agent UL-FS 49 attenuates ischemic regional myocardial dysfunction and reduces infarct size in swine: comparison with the $\beta$-blocker atenolol. $J$ Cardiovasc Pharmacol 1995; 25: 216-28.

21. Samaja M, Allibardi S, Milano G, Neri G, Grassi B, Gladden LB, Hogan MC. Differential depression of myocardial function and metabolism by lactate and $\mathrm{H}^{+}$. Am J Physiol 1998: in press

22. Samaja M, Allibardi S, de Jonge R, Chierchia S. High-energy phosphates metabolism and recovery in reperfused ischemic hearts. Eur J Clin Invest 1998: in press

23. Hohl CM, Wimsatt DK, Brierley GP, Altschuld RA. IMP production by ATP-depleted adult rat heart cells. Effects of glycolysis and alpha ${ }_{1}$-adrenergic stimulation. Circ Res 1989; 65: 754-60.

24. Savabi F. Free creatine available to the creatine phosphate energy shuttle in isolated rat atria. Proc Natl Acad Sci USA 1988; 85: 7476-80. 